\title{
Competitive Photoelectrochemical Methanol and Water Oxidation with Hematite Electrodes
}

Benjamin Klahr ${ }^{\#}$, Sixto Gimenez ${ }^{{ }^{*}}$, Omid Zandi ${ }^{\ddagger}$, Francisco Fabregat-Santiago, ${ }^{\dagger}$ Thomas Hamann $^{\star *}$

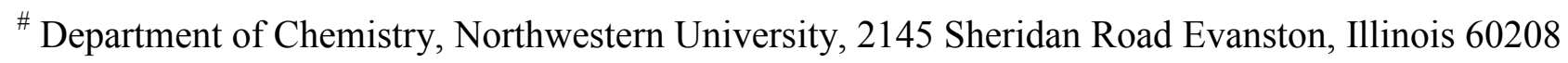

†Photovoltaics and Optoelectronic Devices Group, Departament de Física, Universitat Jaume I, 12071 Castelló, Spain

‡Department of Chemistry, Michigan State University, 578 S Shaw Lane, East Lansing, MI 48824-1322

*Email: sjulia@fca.uji.es, hamann@,chemistry.msu.edu

\begin{abstract}
Photocatalytic water and methanol oxidation were studied at thin film hematite electrodes synthesized by Atomic Layer Deposition (ALD). Systematic photoelectrochemical characterization along with $\mathrm{O}_{2}$ evolution measurements were carried out in order to better understand the mechanisms of both water and methanol oxidation at hematite electrodes. For methanol-water mixtures, water and methanol are oxidized competitively with each other, allowing the detection and assignment of distinct surface states, during methanol and water oxidation. The measurement of different surface states for methanol and water oxidation, along with the absence of measurable surface states in an inert acetonitrile electrolyte, clearly shows that the detected surface states are chemically distinct reaction intermediates of water or methanol oxidation.
\end{abstract}




\section{Introduction}

Solar energy driven hydrogen production has emerged as one of the most promising candidates to eventually supplant fossil fuel combustion as the chemical fuel of the future, primarily because solar energy is an essentially inexhaustible, decentralized and environmentally benign resource. ${ }^{1}$ This process can be carried out using a photoelectrochemical cell with semiconductor electrodes immersed in water where the photo-generated electrons and holes are directly used to reduce and oxidize water, respectively. ${ }^{2}$ This scheme involves the spatial separation of the generated gases $\left(\mathrm{O}_{2}\right.$ and $\left.\mathrm{H}_{2}\right)$ and consequently the probability of back reactions to form $\mathrm{H}_{2} \mathrm{O}$ from the evolved gases is significantly decreased. Among the various semiconductor materials tested as photoanodes, hematite $\left(\alpha-\mathrm{Fe}_{2} \mathrm{O}_{3}\right)$ has received a lot of attention due to its combination of sufficiently broad visible light absorption (up to $590 \mathrm{~nm}$ ), excellent stability under caustic operating conditions and a valence band positioned sufficiently low to oxidize water. ${ }^{3,4}$ Some limitations related to the short collection length of minority carriers have been addressed by nanostructuring, encompassing the orthogonalization of light absorption and minority carrier drift-diffusion directions, as well as alloying strategies. ${ }^{5-9}$ Despite recent advances in charge separation, charge collection at the electrode surface has been shown to be a limiting reaction in the overall water splitting process. ${ }^{10}$

In order to boost the efficiency of water splitting photoelectrochemical devices, allowing them to become a viable technology, a detailed understanding of the charge transfer dynamics leading to water oxidation is compulsory. Recent studies on $\mathrm{Fe}_{2} \mathrm{O}_{3}$ have provided interesting insights into the oxidation mechanisms, recognizing the relevance of surface intermediates for water splitting. ${ }^{11-14}$ We recently developed a general physical model, which explicitly includes the existence of a surface state at the semiconductor/liquid interface. This model successfully describes the accumulation of holes at the surface of the semiconductor as an intrinsic part of the water oxidation reaction. ${ }^{15}$ When an efficient hole scavenger is placed in the solution, such as $\left[\mathrm{Fe}(\mathrm{CN})_{6}\right]^{3-/ 4-}$, this surface state does not participate in the oxidation process and direct valence band hole transfer to the solution is the dominant oxidation mechanism. ${ }^{16}$ Note that this interpretation is not generally accepted, with others suggesting hole trapping at the surface is a process in parallel with direct hole transfer to water. ${ }^{11,17-19}$ 
Methanol $\left(\mathrm{CH}_{3} \mathrm{OH}\right)$ oxidation in the presence of $\mathrm{H}_{2} \mathrm{O}$ is a well-studied process, particularly for its relevance for the development of methanol based fuel cells. ${ }^{20}$ Methanol has also attracted considerable attention for fundamental studies oriented to the photocatalytic elimination of organic compounds in polluted water and air. ${ }^{21}$ Additionally, it has been widely employed as a sacrificial hole scavenger for $\mathrm{TiO}_{2}$, its oxidation leading to the formation of highly reducing hydroxymethyl radicals and consequently to current-doubling. ${ }^{22}$ These radicals can further decompose or couple into added value compounds by complex reaction mechanisms ${ }^{23}$ and subsequent decomposition can take place by a direct or indirect mechanism. ${ }^{24-26}$ In addition, methanol has recently been investigated as a model system of wastewater whose oxidation offers an alternative hydrogen source. ${ }^{27}$

The present study aims to further understand the mechanisms of water and methanol photo-induced oxidation on hematite electrode surfaces. Specifically, the role of a surface state in both media will be resolved, and correlated with the relative rates of water and methanol oxidation. Comparison to an inert acetonitrile electrolyte is also presented which allows confirmation of the assignment of surface states.

\section{Experimental}

Hematite electrodes ( $\sim 60 \mathrm{~nm}$ thick) were deposited by atomic layer deposition (ALD) and characterized using a previously described procedure. ${ }^{15}$ The electrodes were measured in contact with aqueous electrolytes containing a $0.1 \mathrm{M}$ phosphate buffer ( $\mathrm{pH}$ 6.9) with $0.2 \mathrm{M} \mathrm{KCl}$ as supporting electrolyte. This aqueous electrolyte contained varying amounts of methanol $\left(\mathrm{CH}_{3} \mathrm{OH}\right)$. Electrolytes containing only methanol as the solvent also contained $0.2 \mathrm{M}$ tetrabutylammonium chloride as supporting electrolyte. The anhydrous methanol and anhydrous acetonitrile solutions were prepared and sealed in an electrochemical cell under nitrogen in a glove box to minimize the water content. Experiments were also performed with $\mathrm{pH} 13.6(1 \mathrm{M} \mathrm{KOH})$ solutions and with different electrodes which all showed the same trends.

Photoelectrochemical and impedance measurements made in aqueous electrolytes were made using a homemade saturated $\mathrm{Ag} / \mathrm{AgCl}$ reference electrode. Those made in the anhydrous methanol electrolyte were made using a commercial Ag/ $\mathrm{AgCl}$ electrode (ESA 66-EE009 "no leak"). Both electrodes were calibrated to a saturated 
calomel electrode (Koslow Scientic) and tested regularly in a $\left[\mathrm{Fe}(\mathrm{CN})_{6}\right]^{3-/ 4-}$ solution to ensure consistency. A platinum mesh electrode was used as the counter electrode. Unless noted otherwise, measurements were made under 1 sun illumination (AM 1.5, $100 \mathrm{~mW} \mathrm{~cm}^{-2}$ ). Cyclic voltammetry (CV) measurements were carried out immediately after the electrode was held at a positive potential $(1.6 \mathrm{~V}$ vs $\mathrm{Ag} / \mathrm{AgCl}$ for aqueous electrolytes, $1.8 \mathrm{~V}$ vs $\mathrm{Ag} / \mathrm{AgCl}$ for the methanol electrolyte, and $1.5 \mathrm{~V}$ vs $\mathrm{Ag} / \mathrm{AgCl}$ for acetonitrile electrolyte) and 1 sun illumination for 60 seconds. This is expected to fully oxidize the surface intermediates. Immediately before scanning the CV, the light is turned off and the CV measurement is made in the dark. For the anhydrous acetonitrile electrolyte, a positive potential of $1.6 \mathrm{~V}$ vs $\mathrm{Ag} / \mathrm{AgCl}$ was applied for 2 hours in order to oxidize any trace $\mathrm{H}_{2} \mathrm{O}$ in the solution or adsorbed on the electrode surface. Chopped light $J-V$ curves were measured at a scan rate of $75 \mathrm{mV} / \mathrm{s}$ and the light was chopped every $266 \mathrm{~ms}$. The current was sampled at a rate of $500 \mathrm{~Hz}$. Steady state $J-V$ curves were measured at $20 \mathrm{mV} / \mathrm{s}$. In order to deconvolute the chopped light $J-V$ curve from potential, constant potential transients were measured after turning the light on (where the anodic current is measured) and turning the light off (where the cathodic current is measured). These transients are labeled the anodic and cathodic transients respectively. The current was sampled at a rate of $1000 \mathrm{~Hz}$. Impedance measurements were measured at different applied biases using a perturbation amplitude of $10 \mathrm{mV}$. The frequency range was $10 \mathrm{kHz}-10 \mathrm{mHz}$. Data were fit using Zview software (Scribner Associates). The light source was a $450 \mathrm{~W}$ Xe arc lamp (Horiba Jobin Yvon). An AM 1.5 solar filter (Sciencetech Inc.) was used to simulate sunlight at $100 \mathrm{~mW} \mathrm{cm-2} \mathrm{(1} \mathrm{sun).} \mathrm{The} \mathrm{pH} \mathrm{was} \mathrm{determined} \mathrm{with}$ a Crison Basic $20 \mathrm{pH}$ meter.

Oxygen measurements were made with an Ocean Optics spectrophotometer using a FOSPOR fluorescent patch. The electrode was illuminated at 2 suns to produce more oxygen and increase the signal to noise ratio. The theoretical amount of oxygen produced was calculated by assuming that 4 holes are required to produce 1 molecule of oxygen.

\section{Results}


Figure 1(a) shows the current density, $J$, vs. applied voltage, $V$, curves of $\mathrm{Fe}_{2} \mathrm{O}_{3}$ in contact with electrolytes with varying concentrations of $\mathrm{CH}_{3} \mathrm{OH}$. When $\mathrm{CH}_{3} \mathrm{OH}$ is added to $\mathrm{H}_{2} \mathrm{O}$, a slight cathodic shift of the photocurrent onset takes place (see insert of Figure 1a), in agreement with observations made by other researchers. ${ }^{11}$ For anhydrous methanol, however, there is a shallow photocurrent onset observed at a similar potential $(0.7 \mathrm{~V}$ vs $\mathrm{Ag} / \mathrm{AgCl})$, followed by a steeper current onset which mimics the shape measured with water oxidation at hematite electrodes. Surprisingly, there was an anodic shift of approximately $300 \mathrm{mV}$ which was needed to sustain a given photocurrent density of $200 \mu \mathrm{A} \mathrm{cm}^{-2}$ compared to water based electrolytes. This result is in contrast to literature results of hematite photoelectrodes in contact with good hole scavengers, such as $\left[\mathrm{Fe}(\mathrm{CN})_{6}\right]^{3-, 4-}$ and $\mathrm{H}_{2} \mathrm{O}_{2}{ }^{28,29}$

A fluorescence probe was used to measure the amount of $\mathrm{O}_{2}$ produced, which can be used to evaluate the faradaic efficiency of $\mathrm{H}_{2} \mathrm{O}$ oxidation. The $\mathrm{O}_{2}$ concentration was measured at an applied potential of $1.4 \mathrm{~V}$ vs $\mathrm{Ag} / \mathrm{AgCl}$ for $\mathrm{H}_{2} \mathrm{O}$ and $\mathrm{CH}_{3} \mathrm{OH}-\mathrm{H}_{2} \mathrm{O}$ mixture electrolytes and $1.6 \mathrm{~V}$ vs $\mathrm{Ag} / \mathrm{AgCl}$ for the $\mathrm{CH}_{3} \mathrm{OH}$ electrolyte such that the photocurrents were approximately equal. This potential difference also accounts for the difference in the flat band potential, $E_{\mathrm{FB}}$, between aqueous and methanol based electrolytes, vide infra. In the case of the aqueous electrolyte, the faradaic efficiency due to $\mathrm{O}_{2}$ production is approximately unity as shown in Figure 1(b) and Table 1. As increasing amounts of $\mathrm{CH}_{3} \mathrm{OH}$ are added to $\mathrm{H}_{2} \mathrm{O}$, the faradaic efficiency due to $\mathrm{O}_{2}$ generation decreased where no $\mathrm{O}_{2}$ generation could be detected in anhydrous $\mathrm{CH}_{3} \mathrm{OH}$. This is expected since the oxidation of $\mathrm{CH}_{3} \mathrm{OH}$ should produce formaldehyde or $\mathrm{CO}_{2}$, not $\mathrm{O}_{2} \cdot{ }^{26,30,31}$ Interestingly, a significant amount of $\mathrm{O}_{2}$ was generated even with large concentrations of $\mathrm{CH}_{3} \mathrm{OH}$. A summary of the amount of $\mathrm{O}_{2}$ measured for different $\mathrm{CH}_{3} \mathrm{OH}$ concentrations at applied potentials of 0.75 and $1.4 \mathrm{~V} \mathrm{vs} \mathrm{Ag} / \mathrm{AgCl}$ can be seen in Table 1. Relative rates, $v_{R}$, for $\mathrm{CH}_{3} \mathrm{OH}$ oxidation compared to water oxidation was calculated by the equation $v_{\mathrm{R}}=\left(\frac{1-\mathrm{FE}}{\left[\mathrm{CH}_{3} \mathrm{OH}\right]}\right)\left(\frac{\mathrm{FE}}{\left[\mathrm{H}_{2} \mathrm{O}\right]}\right)^{-1}$, where $F E$ is the faradaic efficiency for $\mathrm{O}_{2}$ generation, and can also be found in Table 1. Despite an obvious preference for $\mathrm{CH}_{3} \mathrm{OH}$ oxidation compared to $\mathrm{H}_{2} \mathrm{O}$ oxidation based on the relative rates shown in Table 1 , the overall rate (current) is not significantly altered by adding $\mathrm{CH}_{3} \mathrm{OH}$ to $\mathrm{H}_{2} \mathrm{O}$ as shown in figure 1a. Poor current 
onset potentials still exist with $\mathrm{CH}_{3} \mathrm{OH}$ in solution, showing that it is not acting as a fast and model hole collector as others have suggested. ${ }^{11}$
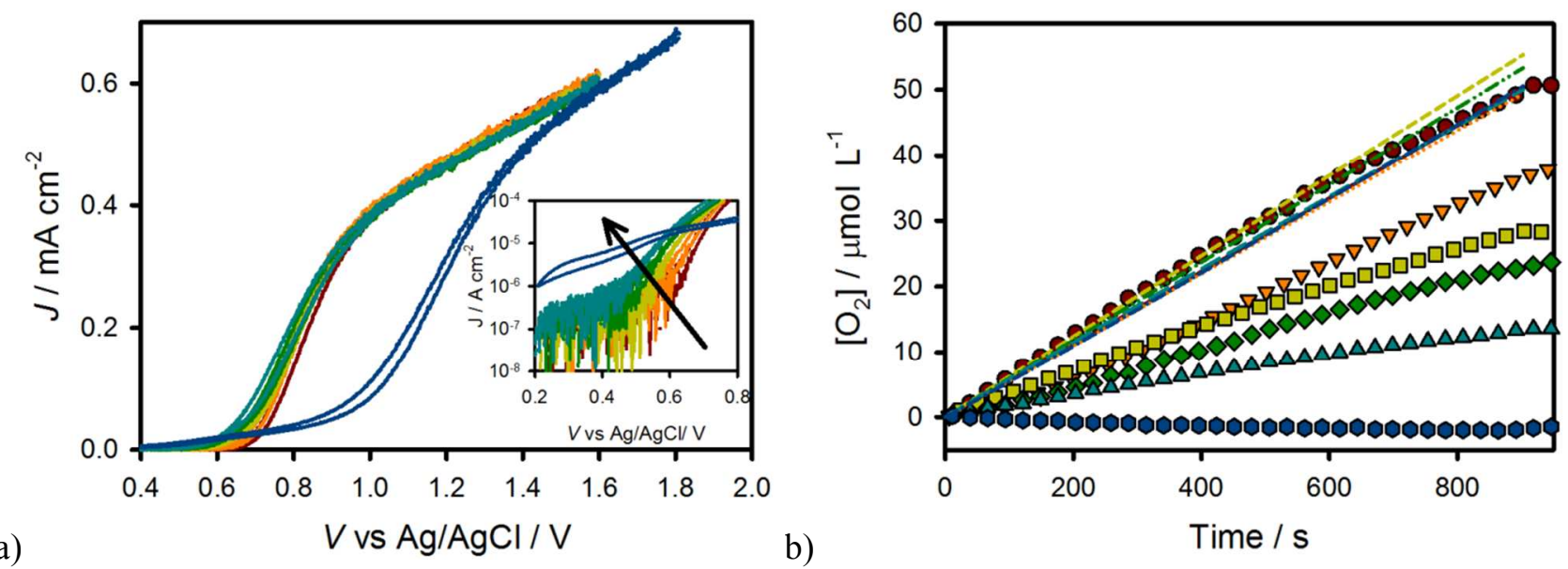

Figure 1. a) $J-V$ curves of a hematite electrode under 1 sun illumination in contact with $\mathrm{H}_{2} \mathrm{O}$ (red), $0.2 \mathrm{M} \mathrm{CH}_{3} \mathrm{OH}$ (orange), $2 \mathrm{M} \mathrm{CH}_{3} \mathrm{OH}$ (yellow), $5 \mathrm{M} \mathrm{CH}_{3} \mathrm{OH}$ (green), $10 \mathrm{M} \mathrm{CH}_{3} \mathrm{OH}$ (teal), and $\mathrm{CH}_{3} \mathrm{OH}$ (blue) vs $\mathrm{Ag} / \mathrm{AgCl}$. b) Theoretical oxygen produced under 2 sun illumination (lines) and measured $\mathrm{O}_{2}$ concentration (shapes) for a hematite electrode in contact with $\mathrm{H}_{2} \mathrm{O}$ (solid line and circles), $0.2 \mathrm{M} \mathrm{CH}_{3} \mathrm{OH}$ (dotted line and downward pointing triangles), $2 \mathrm{M} \mathrm{CH}_{3} \mathrm{OH}$ (short dashed line and squares), $5 \mathrm{M} \mathrm{CH}_{3} \mathrm{OH}$ (double dotted dashed line and diamonds), $10 \mathrm{M} \mathrm{CH}_{3} \mathrm{OH}$ (long dashed line and upward pointing triangles), and $\mathrm{CH}_{3} \mathrm{OH}$ (single dotted line and hexagons). Applied potentials for $\mathrm{O}_{2}$ concentration measurement was $1.4 \mathrm{~V}$ vs $\mathrm{Ag} / \mathrm{AgCl}$ for the $\mathrm{H}_{2} \mathrm{O}$ and $5 \mathrm{M} \mathrm{CH} \mathrm{CH}_{3} \mathrm{OH}$ electrolytes and $1.6 \mathrm{~V}$ vs $\mathrm{Ag} / \mathrm{AgCl}$ for the $\mathrm{CH}_{3} \mathrm{OH}$ electrolyte.

Table 1. Summary of faradaic efficiency due to $\mathrm{O}_{2}$ generation for varying concentrations of $\mathrm{CH}_{3} \mathrm{OH}$ in $\mathrm{H}_{2} \mathrm{O}$

\begin{tabular}{|c|c|c|c|c|c|c|c|c|c|}
\hline \multirow[b]{2}{*}[\mathrm{MeOH}]{$/ \mathbf{M}$} & \multirow[b]{2}{*}[\mathrm{H}_{2}\mathrm{O}]{$/ \mathrm{M}$} & \multicolumn{4}{|c|}{$0.75 \mathrm{~V}$ vs $\mathrm{Ag} / \mathrm{AgCl}$} & {$\left[\underline{O}_{2}\right] / \mathrm{mic}$} & $\begin{array}{r}1.4 \mathrm{~V} \mathrm{vs} \\
\text { moles } \mathrm{L}^{-1} \\
\end{array}$ & $\mathrm{~g} / \mathrm{AgCl}$ & \\
\hline & & Theoretical & Measured & $\begin{array}{c}\mathrm{O}_{2} \text { Faradaic } \\
\text { Efficiency }\end{array}$ & $\begin{array}{c}\text { Relative } \\
\text { Rate* }\end{array}$ & Theoretical & Measured & $\begin{array}{c}\mathrm{O}_{2} \text { Faradaic } \\
\text { Efficiency }\end{array}$ & $\begin{array}{c}\text { Relative } \\
\text { Rate* }\end{array}$ \\
\hline 0.0 & 55.5 & 11.17 & 11.11 & $99.42 \%$ & & 50.13 & 49.81 & $99.36 \%$ & \\
\hline 0.2 & 55.2 & 7.90 & 5.41 & $68.48 \%$ & 133.48 & 49.20 & 36.00 & $73.17 \%$ & 106.33 \\
\hline 2.0 & 50.2 & 12.90 & 4.01 & $31.09 \%$ & 56.52 & 55.15 & 28.35 & $51.40 \%$ & 24.11 \\
\hline 5.0 & 46.7 & 10.77 & 1.89 & $17.55 \%$ & 41.35 & 53.15 & 22.80 & $42.90 \%$ & 11.71 \\
\hline 10.0 & 37.8 & 7.29 & 0.59 & $8.06 \%$ & 37.65 & 49.86 & 15.94 & $31.97 \%$ & 7.02 \\
\hline
\end{tabular}

* Ratio of $\mathrm{CH}_{3} \mathrm{OH}$ to $\mathrm{H}_{2} \mathrm{O}$ oxidation 
In order to account for any differences in energetics (band edge movement) due to the different electrolytes, impedance spectroscopy (IS) measurements were performed in the dark. Mott Schottky plots were generated for pure $\mathrm{H}_{2} \mathrm{O}, \mathrm{CH}_{3} \mathrm{OH}$ and $5 \mathrm{M} \mathrm{CH} \mathrm{CH}_{3} \mathrm{OH}$ electrolytes by fitting the impedance spectra to a Randle's circuit. Since the electrode, and therefore dopant density, is the same for all electrolytes, the slope of the Mott Schottky is expected to be independent of the electrolyte. This is indeed the case, apparent from inspection of figure 2a. Therefore, to fit the Mott Schottky plots, the slopes of all 3 electrolytes were fit globally. The extracted dopant density, $N_{\mathrm{D}}$, was calculated to be $5.3 \times 10^{18} \mathrm{~cm}^{-3}$, in good agreement with previous results. ${ }^{15,16}$ The flat band potential was also extracted from the Mott Schottky plots and can be seen in table 2. The measured $E_{\mathrm{FB}}$ for the aqueous electrolytes are nearly equal. In anhydrous $\mathrm{CH}_{3} \mathrm{OH}$ however, the $E_{\mathrm{FB}}$ is shifted $\sim 200 \mathrm{mV}$ positive. Part of the difference in $J-V$ curves can therefore be attributed to a shift in the band energies. In order to carry out an adequate comparison between the different electrolytes, potentials were normalized to their respective $E_{\mathrm{FB}}$ 's. Normalized $J-V$ curves are shown in Figure 2b. At high positive applied potentials, the current achieved in all electrolytes is approximately equal. We have suggested previously that in these thin films, at high applied potential, the photocurrent is controlled by the rate of photogenerated holes that reach the surface; i.e. water oxidation is not the rate limiting step. Thus, addition of a fast hole collector (e.g. $\mathrm{H}_{2} \mathrm{O}_{2}, \mathrm{CH}_{3} \mathrm{OH}, \mathrm{Fe}(\mathrm{CN})_{6}{ }^{3-/ 4-}$ ) should not increase the current at a given positive Fermi level. Even when correcting for the change in the $E_{\mathrm{FB}}$, the steep current onset of anhydrous $\mathrm{CH}_{3} \mathrm{OH}$ oxidation occurs at more positive potentials compared to $\mathrm{H}_{2} \mathrm{O}$ oxidation suggesting that photoelectrochemical differences cannot be solely attributed to differences in the position of the bands of $\mathrm{Fe}_{2} \mathrm{O}_{3}$ in different media. 

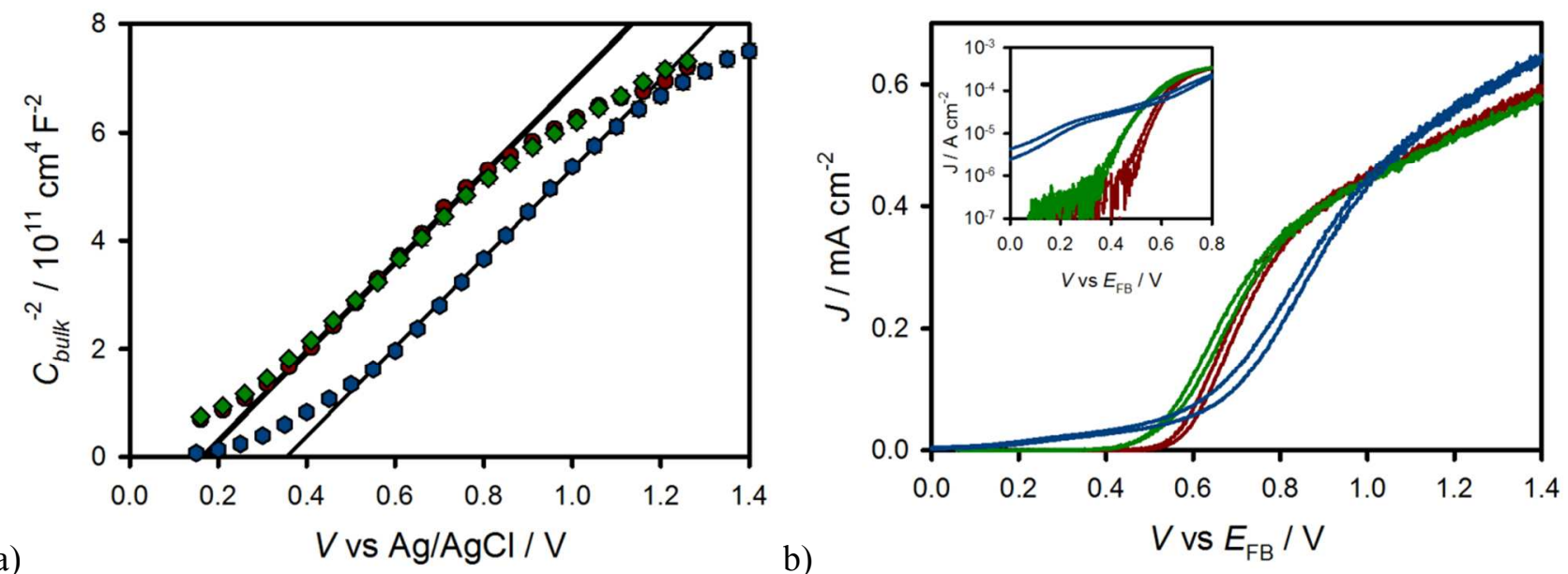

Figure 2. (a) Mott Schottky plot of $C_{\text {bulk }}$ measured in the dark for $\mathrm{H}_{2} \mathrm{O}$ (red circles), $5 \mathrm{M} \mathrm{CH}_{3} \mathrm{OH}$ (green diamonds) and $\mathrm{CH}_{3} \mathrm{OH}$ electrolytes (blue hexagons). (b) $J-V$ curves of a hematite electrode under 1 sun illumination in contact with $\mathrm{H}_{2} \mathrm{O}$ (red), $5 \mathrm{M} \mathrm{CH}_{3} \mathrm{OH}$ (green) and $\mathrm{CH}_{3} \mathrm{OH}$ (blue) plotted vs $E_{\mathrm{FB}}$.

Table 2. Summary of the Mott-Schottky analysis from impedance spectroscopy measurements carried out in the dark including the flat band potential $\left(E_{\mathrm{FB}}\right)$ and the donor density $\left(N_{\mathrm{D}}\right)$ of hematite phototoelectrodes in different solution media.

\begin{tabular}{|c|c|c|}
\hline & $E_{\mathrm{FB}} \mathrm{vs} \mathrm{Ag} / \mathrm{AgCl}(\mathrm{mV})$ & $N_{\mathrm{D}}\left(\cdot 10^{18} \mathrm{~cm}^{-3}\right)$ \\
\hline $\mathrm{H}_{2} \mathrm{O}$ & 137 & 5.3 \\
\hline $5 \mathrm{M} \mathrm{CH}_{3} \mathrm{OH}$ & 143 & 5.3 \\
\hline $\mathrm{CH}_{3} \mathrm{OH}$ & 330 & 5.3 \\
\hline
\end{tabular}

In order to get more detailed mechanistic information of water and methanol oxidation, impedance spectroscopy measurements were also performed under illumination conditions. Aqueous electrolytes produced Nyquist plots with two clearly distinguishable semicircles near the current onset potential (supporting info, Figure SI2). A physical model which has been previously developed for the interpretation of charge transfer from hematite electrodes to water can be seen in the form of an equivalent circuit, EC, shown in Figure $2 \mathrm{a}^{15,16}$ This $^{1}$ general model specifically includes the presence of a surface state able to capture conduction band electrons and valence band holes; the trapping-detrapping kinetics are related to $R_{\text {trap }}$, and the occupancy of the surface state 
produces a chemical capacitance, $C_{\mathrm{ss}}$. Charge transfer takes place through this surface state with a charge transfer resistance, $R_{\mathrm{ct}, \mathrm{ss}}$. Additionally, a bulk capacitance, $C_{\mathrm{bulk}}$, accounts for the space charge capacitance. This EC was used to fit IS data gathered in $\mathrm{H}_{2} \mathrm{O}$ and $5 \mathrm{M} \mathrm{CH}_{3} \mathrm{OH}$ electrolytes. For the pure $\mathrm{H}_{2} \mathrm{O}$ electrolyte, a clear peak in $C_{\text {ss }}$ develops with voltage which is coincident with the current onset potential (Figure 4a). This peak highlights the requirement for charge accumulation at the surface for water oxidation to occur, and has been pointed out by other researchers. ${ }^{32-34}$ When $\mathrm{CH}_{3} \mathrm{OH}$ is added to the aqueous solution, a $C_{\text {ss }}$ peak is also observed, at the same potential vs $E_{\mathrm{FB}}$ as shown in Figure 4(a). The magnitude of this peak is approximately two times lower, however, reflecting that fewer holes are accumulated at the surface in this state. This result is further corroborated by CV measurements presented below. This result is also in good agreement with the $\mathrm{O}_{2}$ evolution measurements displayed in Figure 1(b), which indicated that both oxidation of water and methanol lead to the obtained photocurrent. A corresponding decrease in $\mathrm{C}_{\mathrm{ss}}$ and $\mathrm{O}_{2}$ generation with the addition of $\mathrm{CH}_{3} \mathrm{OH}$ further shows that water oxidation occurs through a surface state intermediate. Also, a decrease in the measured $C_{\mathrm{ss}}$ for $\mathrm{H}_{2} \mathrm{O}-\mathrm{CH}_{3} \mathrm{OH}$ mixtures implies that methanol oxidation competes against water oxidation through a different pathway. Despite methanol reducing the measured capacitance of surface states due to water oxidation, two capacitive features are still observed in impedance spectra measured in the anhydrous methanol electrolyte (see Supporting Information, Figure SI 2b). Since it appears that charge transfer to methanol occurs through a different pathway than that of water, we invoke another possible EC to describe anhydrous methanol oxidation at hematite electrodes, which is shown in figure $3 \mathrm{~b}$. This model was chosen due to its corroboration with photoelectrochemical experiments discussed below. As in the EC used to describe $\mathrm{H}_{2} \mathrm{O}$ oxidation, this EC still contains a surface state capacitance, $C_{\mathrm{ss}}$ and a resistance of transfer to those surface states, $R_{\text {trap }}$, based on the observation of 2 clear capacitances in the Nyquist plot. However, instead of charge transfer through those surface sates, this EC contains a separate charge transfer resistance which is not associated with those surface states, $R_{\mathrm{ct}}$. This model could imply direct charge transfer from the valence band of the hematite to methanol through an outer-sphere electron transfer mechanism. However a more likely possibility is that a surface state or surface intermediate is generated, such as a surface adsorbed methoxy species $\left(\mathrm{Fe}-\mathrm{O}-\mathrm{CH}_{3}\right)$ which is the analogous adsorbed species responsible for charge transfer for photogenerated holes on $\mathrm{TiO}_{2}{ }^{30}$ This mechanism could be interpreted as a single charge transfer resistance if the 
steady state concentration is very low, resulting in a very low or immeasurable capacitance. By using this model, the obtained trap capacitance shows a double peak feature, with significantly lower intensity compared to water based electrolytes (Figure 4a).

a)

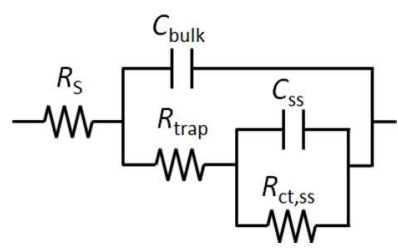

b)

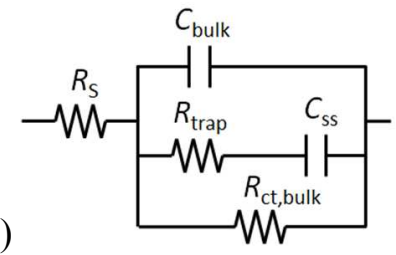

c)

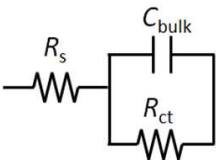

Figure 3. (a) Simplified model involving hole transfer through a surface state (b) Simplified model involving direct hole transfer from valence band (c) Randles circuit

The values of charge transfer resistance $R_{\mathrm{ct}}$ are shown in Supporting Information, Figure SI3(a) for the different electrolytes. At low bias $\left(0-0.4 \mathrm{~V}\right.$ vs $\left.\mathrm{E}_{\mathrm{FB}}\right)$, the addition of $\mathrm{CH}_{3} \mathrm{OH}$ to $\mathrm{H}_{2} \mathrm{O}$ reduces the charge transfer resistance. This is because we are measuring the charge transfer resistance from the surface states (due to water oxidation) which is reduced with the addition of $\mathrm{CH}_{3} \mathrm{OH}$, as shown by $\mathrm{O}_{2}$ evolution measurements and $C_{\mathrm{ss}}$. In other words, for a constant potential, the resistance of charge transfer to water through water oxidation intermediates is reduced because the current due to water oxidation is reduced for an increasing amount of $\mathrm{CH}_{3} \mathrm{OH}$. Compared to aqueous electrolytes, $R_{\mathrm{ct}}$ for methanol oxidation is higher, positive of $0.4 \mathrm{~V}$ vs $\mathrm{E}_{\mathrm{FB}}$, consistent with the lower photocurrents measured at more anodic bias. The values of $R_{\text {trap }}$ are compiled in Supporting Information, Figure SI3(b). $R_{\text {trap }}$ was found to be identical for both water based electrolytes and higher for anhydrous methanol between $0 \mathrm{~V}$ vs $\mathrm{E}_{\mathrm{FB}}$ and $0.7 \mathrm{~V}$ vs $\mathrm{E}_{\mathrm{FB}}$. This is likely because hole transfer to $\mathrm{CH}_{3} \mathrm{OH}$ is less probable due to the lower $C_{\mathrm{ss}}$ and corresponding accepting states.

Confirmation of the fits can be gained by plotting the total resistance from impedance $\left(R_{\mathrm{tot}}=R_{\mathrm{s}}+R_{\mathrm{trap}}+R_{\mathrm{ct}, \mathrm{ss}}\right.$ for aqueous electrolytes and $R_{\mathrm{tot}}=R_{\mathrm{s}}+R_{\mathrm{ct} \text {,bulk }}$ for the $\mathrm{CH}_{3} \mathrm{OH}$ electrolyte) and comparing that to the resistance calculated from the $J-V$ curves $\left(\mathrm{R}_{\mathrm{tot}}=\mathrm{d} V / \mathrm{d} J\right)$. This plot can be seen in figure $4 \mathrm{~b}$. All electrolytes show $R_{\text {tot }}$ from $J-$ $V$ curves and $R_{\text {tot }}$ from IS are in good general agreement indicating that the main resistances which control the $J-V$ 
are represented in the impedance spectra. It is interesting to note that anhydrous methanol oxidation involves two different $R_{\mathrm{tot}}$ dips, around $0.4 \mathrm{~V}$ vs $E_{\mathrm{FB}}$ and $0.8 \mathrm{~V}$ vs $E_{\mathrm{FB}}$, which appear to be related to the two small $C_{\mathrm{ss}}$ peaks shown in Figure 4a. This suggests that two different oxidations are being measured; one between 0.2-0.6 V vs $\mathrm{E}_{\mathrm{FB}}$ (see Figure $2 \mathrm{~b}$ ) where the slope of the $J-V$ curve is low, and one above $0.6 \mathrm{~V}$ vs $E_{\mathrm{FB}}$, where the $J-V$ curve takes a similar slope as that of aqueous solutions.

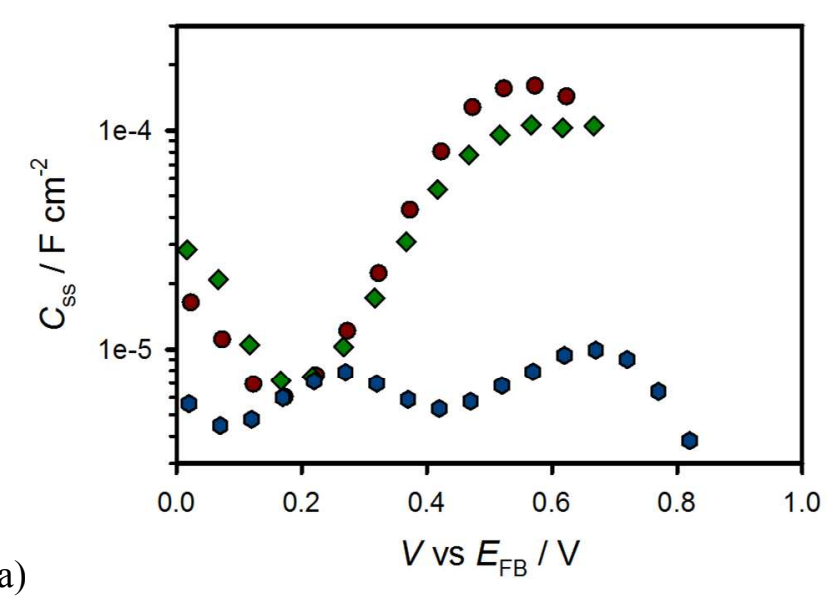

b)

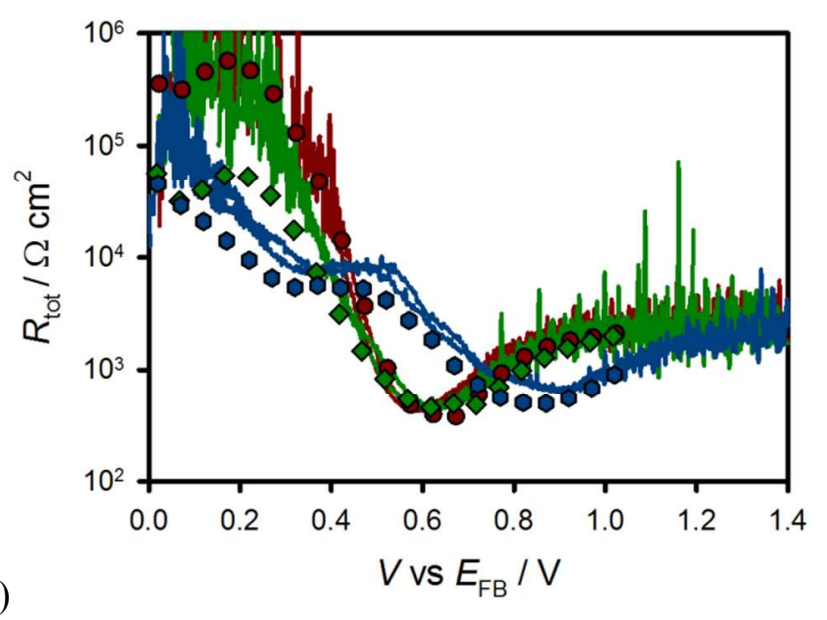

Figure 4. (a) $C_{S s}$ and (b) $R_{t o t}$ vs $E_{\mathrm{FB}}$ extracted from IS analysis under illumination $\left(100 \mathrm{~mW} \cdot \mathrm{cm}^{2}\right)$ for a hematite electrode in contact with $\mathrm{H}_{2} \mathrm{O}$ (red circles) $5 \mathrm{M} \mathrm{CH}_{3} \mathrm{OH}$ in $\mathrm{H}_{2} \mathrm{O}$ (green diamonds) and $\mathrm{CH}_{3} \mathrm{OH}$ (blue hexagons).

Cyclic voltammetry experiments were carried out on $\mathrm{Fe}_{2} \mathrm{O}_{3}$ films to measure surface states as previously reported. ${ }^{16}$ For these measurements a constant high positive bias (1.6 V vs $\mathrm{Ag} / \mathrm{AgCl}$ for aqueous electrolytes and $1.8 \mathrm{~V}$ vs $\mathrm{Ag} / \mathrm{AgCl}$ for methanol electrolyte) was initially applied under illumination to fill the surface states with holes. The light was then turned off and a CV was immediately scanned several times (Supporting information, Figure SI4). Cathodic peaks were observed for all electrolytes on the first scan at potentials similar to the potentials where a $C_{\mathrm{ss}}$ is observed from IS measurements (Figure 5). These peaks are observed at the same energy and with similar relative intensity to those observed in the peaks of $C_{\mathrm{ss}}$ in Figure 4a. Additional figures including data measured in all $\mathrm{CH}_{3} \mathrm{OH}$ electrolytes can be seen in supporting information which show the same trend of decreasing cathodic peak currents with the addition of $\mathrm{CH}_{3} \mathrm{OH}$. On the second scan, these peaks disappear 
because the surface states are not re-oxidized on the timescale of this experiment (supporting information, Figure SI4). The evolution of this peak with scan rate (supporting information, Figure SI5) also confirms its capacitive nature. ${ }^{16}$ Upon zooming in on the cyclic voltammetry curve for methanol (Figure 5 insert), two small peaks are evident, which is consistent with the $C_{\mathrm{ss}}$ measured by IS using the model in figure $3 \mathrm{~b}$. It should be noted that these two peaks were not observed in the IS interpretation using the model in figure 3a (See Supporting Information, Figure SI7). Thus these two peaks corroborate the selection of the equivalent circuit for interpreting $\mathrm{CH}_{3} \mathrm{OH}$ oxidation at the hematite surface.

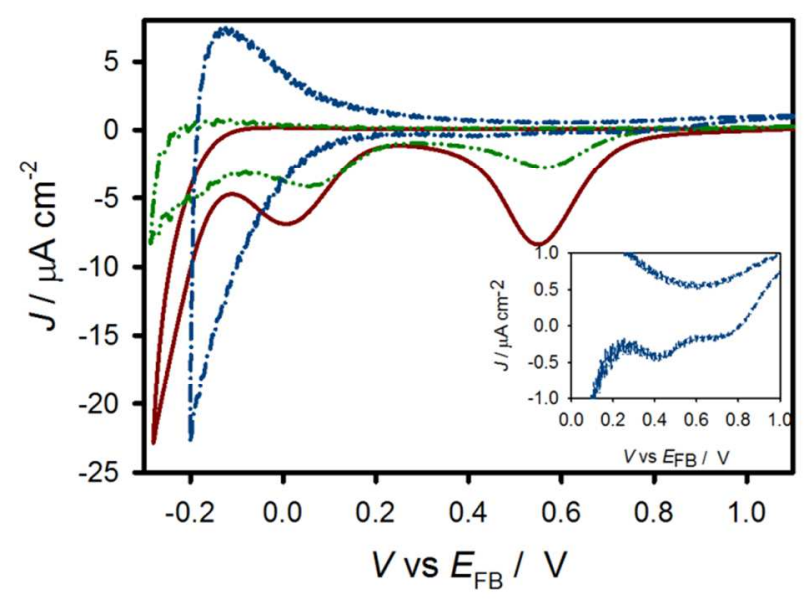

Figure 5. Comparison of the first scan of the $\mathrm{CV}$ measured at $200 \mathrm{mV} / \mathrm{s}$ in $\mathrm{H}_{2} \mathrm{O}$ (red solid line), $5 \mathrm{M} \mathrm{CH}_{3} \mathrm{OH}$ in $\mathrm{H}_{2} \mathrm{O}$ (green double dot dashed line) and $\mathrm{CH}_{3} \mathrm{OH}$ (blue single dot dashed line). A magnified image of the $\mathrm{CH}_{3} \mathrm{OH}$ curve is shown in the insert which shows 2 small peaks.

The cathodic peak measured at $\sim 0.55 \mathrm{~V}$ vs $E_{\mathrm{FB}}$ in the $\mathrm{CVs}$ of Figure 5 along with the $C_{\mathrm{ss}}$ peak observed in IS measurements at the same potential, has been previously attributed to the accumulation of photogenerated holes on the hematite surface in the form of water oxidation intermediates. This peak is always coincident with the water oxidation photocurrent onset and its magnitude is correlated to the water oxidation current; i.e. the peak magnitude reduces with increasing $\mathrm{CH}_{3} \mathrm{OH}$ concentration which competes for photogenerated holes (less water oxidation intermediates form at a given time) (Figure SI6). To further show that these capacitive features are a part of the oxidation intermediates of water and methanol, analogous CV measurements were performed in an 
inert electrolyte, anhydrous acetonitrile, where no hole transfer to solution is expected. The band energy position of the hematite electrode in an acetonitrile electrolyte was controlled through Mott-Schottky measurements, which showed an $\sim 80 \mathrm{mV}$ cathodic shift in the flat band potential compared to aqueous electrolytes (Figure SI8). Illuminated $J-V$ curves of a hematite electrode in contact with anhydrous acetonitrile showed negligible background current ensuring the absence of $\mathrm{H}_{2} \mathrm{O}$ in the electrolyte (Figure 6a). As shown in Figure $6 \mathrm{~b}$ for anhydrous acetonitrile solution, no cathodic peaks were observed above the background in the CV measurements suggesting that the cathodic peak observed under $\mathrm{H}_{2} \mathrm{O}$ oxidation conditions is specific to $\mathrm{H}_{2} \mathrm{O}$ oxidation and not intrinsic to the hematite surface. Interestingly, addition of trace amounts of $\mathrm{H}_{2} \mathrm{O}$ to the acetonitrile electrolyte resulted in the development of a cathodic peak in the CV scans, further confirming the assignment of this capacitive feature to species involved in $\mathrm{H}_{2} \mathrm{O}$ oxidation reaction (see Supporting Information Figure SI8).
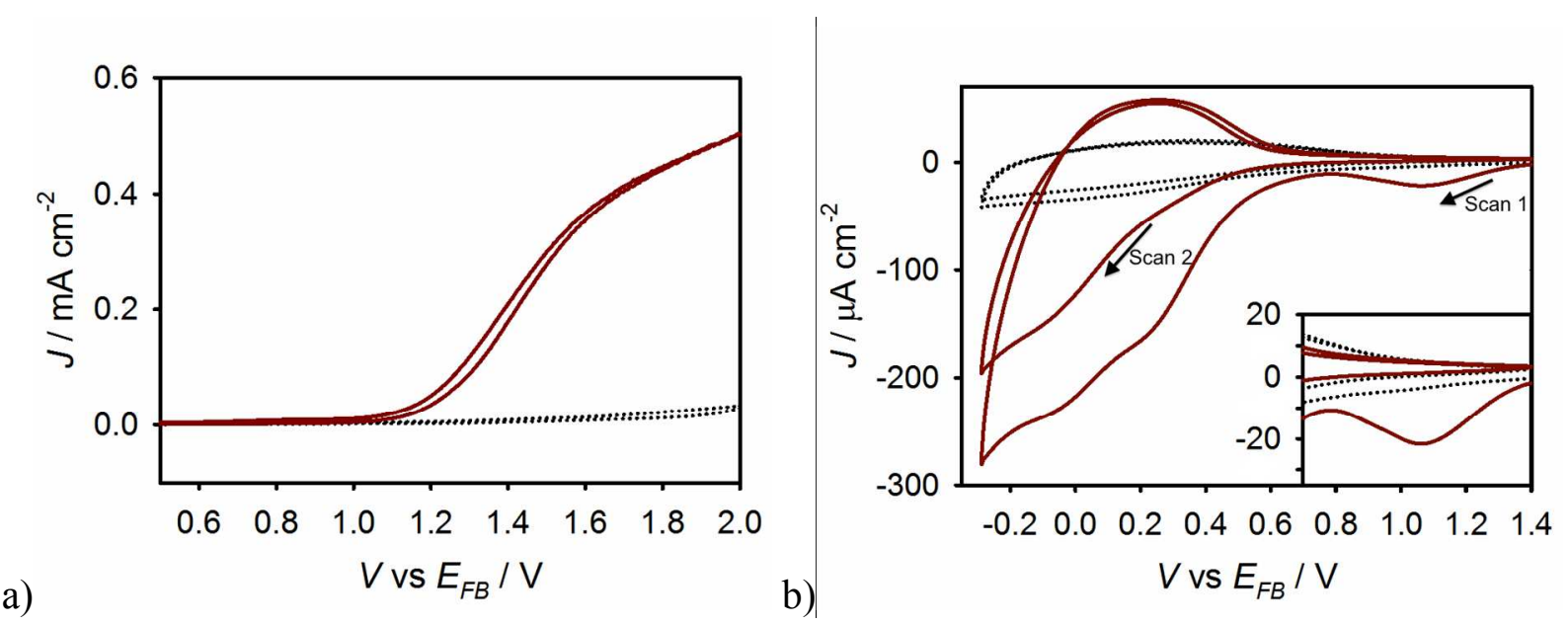

Figure 6. (a) $J-V$ and (b) $\mathrm{CV}$ response of a hematite electrode measured in contact with anhydrous MeCN (black dotted line) and after addition of $10 \mu \mathrm{L} \mathrm{H}_{2} \mathrm{O}(0.2 \% \mathrm{~V})$ to the electrolyte (red solid line). $J-V$ s were measured under 1 sun illumination and CVs were recorded at $500 \mathrm{mV} / \mathrm{s}$ in dark after holding the electrode at $1.5 \mathrm{~V}$ vs $\mathrm{Ag} / \mathrm{AgCl}$ under 1 sun illumination for $60 \mathrm{~s}$.

The capacitive nature of the surface states of both $\mathrm{H}_{2} \mathrm{O}$ and $\mathrm{CH}_{3} \mathrm{OH}$ surface states was examined by transient light experiments. Chopped light $J-V$ curves were obtained and compared to those with constant illumination (Supporting Information, Figure SI9). In all tested electrolytes, the presence of anodic and cathodic transients indicated the presence of surface states. ${ }^{28,35,36}$ These spikes were analyzed quantitatively by switching 
the light on (anodic) and off (cathodic) at a constant potential while measuring the current as a function of time. Examples of current transients can be seen in Figure $7 \mathrm{a}$ and in supporting information, Figures SI10-SI13. Integration of the cathodic current provides a quantitative measurement of the light-induced charge stored in the surface states, which is shown in Figure $7 \mathrm{~b}$, and compared to $C_{\mathrm{ss}}$ measured by IS. The good agreement between the integrated charge from transient measurements with $C_{\mathrm{ss}}$ from IS shows that these two measurements are probing the same species.

Single exponential lifetimes of the cathodic transients were calculated and can be seen in Figure 7c. The lifetimes are approximately equal for $\mathrm{H}_{2} \mathrm{O}$ and $5 \mathrm{M} \mathrm{CH}_{3} \mathrm{OH}$ electrolytes throughout the potential range with the exception of potentials greater than $\sim 0.6 \mathrm{~V}$ vs $E_{\mathrm{FB}}$ where the mixture has lower lifetimes. These decays are attributed to electrons from the conduction band reducing the oxidized surface states. Since the dominant surface state is related to water oxidation, it is not surprising that these measured lifetimes are constant for the two aqueous electrolytes. We note that this result disagrees with Cowan et. al. who showed a decrease in lifetime for a $10 \% \mathrm{CH}_{3} \mathrm{OH}$ in $\mathrm{H}_{2} \mathrm{O}$ solution compared to a $\mathrm{H}_{2} \mathrm{O}$ solution under no applied bias. ${ }^{37}$ It is possible, however, the techniques of transient electrochemistry employed herein and transient absorption spectroscopy employed by Cowan et. al. are measuring different species. In the $\mathrm{CH}_{3} \mathrm{OH}$ electrolyte, the lifetimes of these transients are approximately an order of magnitude lower than those measured in aqueous electrolytes at potentials where photocurrent is measured. This is attributed to an increased rate of recombination to surface $\mathrm{CH}_{3} \mathrm{OH}$ oxidation intermediates compared to surface $\mathrm{H}_{2} \mathrm{O}$ oxidation intermediates. ${ }^{26}$ The lifetimes were also calculated by multiplying the $C_{\mathrm{ss}}$ and $R_{\text {trap }}$ from IS results and are shown in figure $7 \mathrm{c}$ as open shapes. The same general trend is observed between the lifetimes calculated from transient and EIS measurements. 

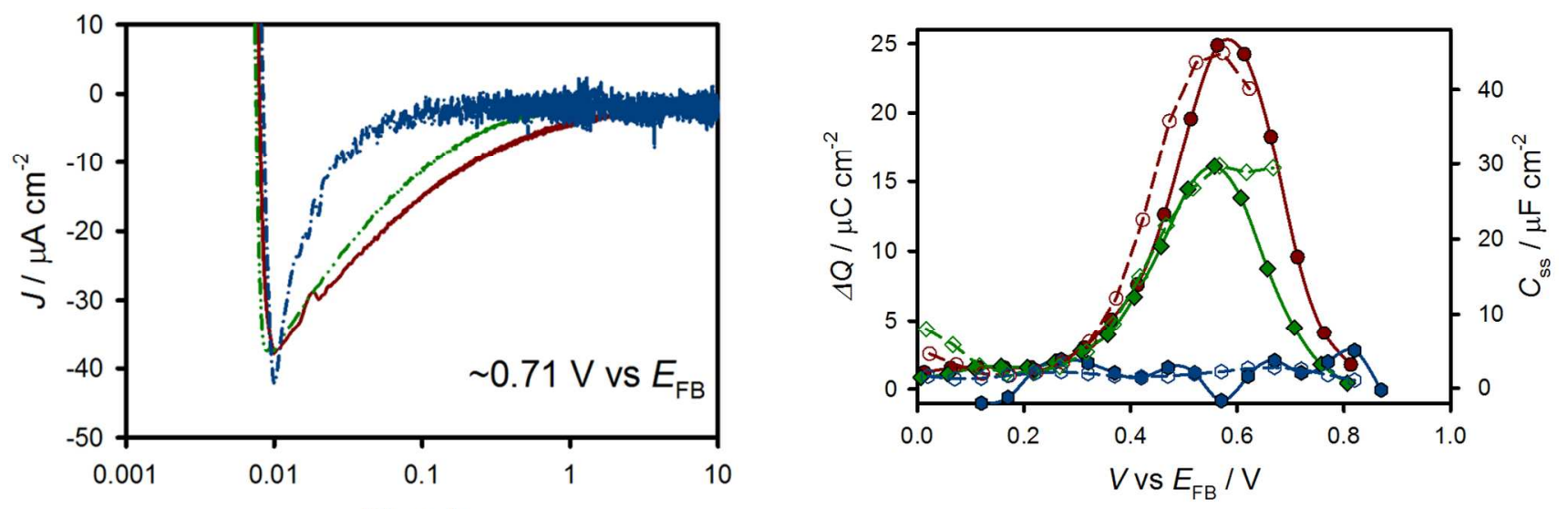

a)

Time / s

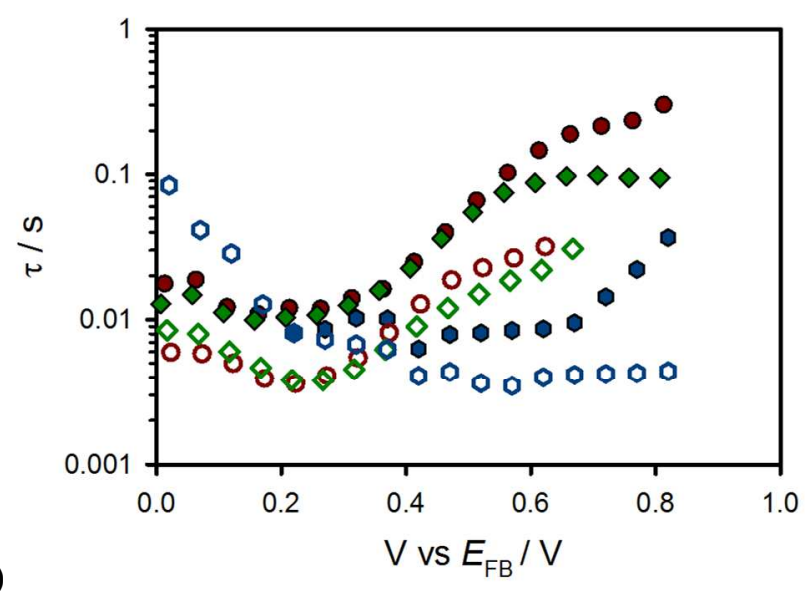

b)

Figure 7. a) Cathodic transients in $\mathrm{H}_{2} \mathrm{O}$ (red solid line), $5 \mathrm{M} \mathrm{CH}_{3} \mathrm{OH}$ in $\mathrm{H}_{2} \mathrm{O}$ (green double dot dashed line) and $\mathrm{CH}_{3} \mathrm{OH}$ (blue single dot dashed line) measured within $5 \mathrm{mV}$ of $0.71 \mathrm{~V}$ vs $E_{\mathrm{FB}}$. b) The calculated charge passed measured by integrating cathodic transients (filled symbols, solid lines) along with $C_{\mathrm{ss}}$ measured by IS (hollow symbols, dashed lines) for a hematite electrode in contact with $\mathrm{H}_{2} \mathrm{O}$ (red circles) $5 \mathrm{M} \mathrm{CH}_{3} \mathrm{OH}$ in $\mathrm{H}_{2} \mathrm{O}$ (green diamonds) and $\mathrm{CH}_{3} \mathrm{OH}$ (blue hexagons). c) Lifetimes of transients fit by a single exponential decay (solid shapes) and by multiplying $C_{\mathrm{ss}}$ and $R_{\text {trap }}$ (open shapes) for $\mathrm{H}_{2} \mathrm{O}$ (red circles), $5 \mathrm{M} \mathrm{CH}_{3} \mathrm{OH}$ (green diamonds), and $\mathrm{CH}_{3} \mathrm{OH}$ (blue hexagons).

From the double peak feature observed for $C_{\mathrm{ss}}$ from IS analysis of anhydrous methanol oxidation, correlated to respective cathodic peaks in the cyclic voltammetry, and dips in the charge transfer resistance $\left(R_{\mathrm{ct}}\right)$ and total resistance $\left(R_{\mathrm{tot}}\right)$, it appears that two surface intermediates are being measured during $\mathrm{CH}_{3} \mathrm{OH}$ oxidation. A recent paper by Baltrusaitis et. al. discusses methanol oxidation on hematite surfaces using theoretical 
calculations for several surface terminations. ${ }^{27}$ Since the electrochemical response of the oxidation of $\mathrm{H}_{2} \mathrm{O}-$ $\mathrm{CH}_{3} \mathrm{OH}$ mixtures is dominated by the redox properties of water surface intermediates (which has been previously discussed in detail), ${ }^{15,16}$ this discussion will focus on the oxidation of the anhydrous $\mathrm{CH}_{3} \mathrm{OH}$ solution. For the $\mathrm{Fe}$ $\mathrm{O}_{3}-\mathrm{R}$ termination of the (0001) surface of hematite (which is the most stable termination under non-aqueous conditions), ${ }^{38}$ anhydrous methanol oxidation at the Fe atom is expected to occur as follows: ${ }^{27}$

$$
\mathrm{CH}_{3} \mathrm{OH}+\mathrm{Fe} \rightarrow \mathrm{CH}_{3} \mathrm{OFe}+\mathrm{H}^{+}+\mathrm{e}^{-}
$$

$\mathrm{CH}_{3} \mathrm{OFe} \rightarrow \mathrm{CH}_{2} \mathrm{OFe}+\mathrm{H}^{+}+\mathrm{e}^{-}$

$\mathrm{CH}_{2} \mathrm{OFe} \rightarrow \mathrm{CHOFe}+\mathrm{H}^{+}+\mathrm{e}^{-}$

$\mathrm{CHOFe} \rightarrow \mathrm{COFe}+\mathrm{H}^{+}+\mathrm{e}^{-}$

Under photoelectrochemical conditions (where $\mathrm{U}=2.1 \mathrm{eV}$ for photogenerated holes in the valence band), steps 1-4 are calculated to be thermodynamically downhill. ${ }^{27}$ While these reactions are thermodynamically favored, insight into the rates cannot be easily determined due to the conflation with electron recombination from electrons in the conduction band to the various surface bound species. The two capacitance peaks observed in IS, and cyclic voltammetry likely represent potentials where a relatively large concentration of surface bound intermediates form due to a balancing of oxidation of holes from the valence band and recombination from electrons in the conduction band. The identity of these two electrochemically observable species is uncertain, although we speculate that each peak is an independent surface species represented in one of equations 1-4. In-situ spectroelectrochemistry has recently been used to examine the identity of water oxidation intermediates at the hematite surface, and could also be employed to study methanol oxidation. ${ }^{17,39}$ In this manner, the precise molecular details of this mechanism are currently being investigated in our lab.

Finally, concomitant water oxidation is required to produce $\mathrm{O}^{*}$ and complete the oxidation of $\mathrm{CO}$ to $\mathrm{CO}_{2}{ }^{27}$ Since this favored mechanism cannot occur in the anhydrous methanol electrolyte, this explains the very low initial photocurrent densities observed for this electrolyte. Further, in the presence of water, the overall 
methanol oxidation cannot proceed faster than the water oxidation reaction required to produce $\mathrm{O}^{*}$, this explains why the addition of methanol does not have a significant effect on the $J-V$ response of methanol-water mixtures: i.e. water oxidation is the rate-limiting step.

\section{Conclusions}

The photooxidation of methanol and water was examined at the surface of model hematite photoanodes synthesized by Atomic Layer Deposition (ALD). A surface capacitance correlated with water oxidation is decreased with the addition of $\mathrm{CH}_{3} \mathrm{OH}$. This reduction in surface states, measured by IS, $\mathrm{CV}$ and transient measurements, combined with corroborating $\mathrm{O}_{2}$ evolution, further confirms that the surface states are actively participating in the hole transfer mechanism to $\mathrm{H}_{2} \mathrm{O}$, as suggested in previous studies. ${ }^{15,16}$ The fact that distinct surface states are measured in anhydrous methanol solutions, and no surface states are measured in an inert anhydrous acetonitrile solution, further proves this point.

\section{Acknowledgements}

TWH thanks the National Science Foundation (CHE-1150378) for support of this research. JB \& FFS acknowledge support by projects from Ministerio de Ciencia e Innovación (MICINN) of Spain (Consolider HOPE CSD2007-00007), Generalitat Valenciana (PROMETEO/2009/058 and the "Institute of Nanotechnologies for Clean Energies", under project ISIC/2012/008). FFS thanks the funding of University Jaume I- Bancaixa (Grant $\mathrm{P} 1 \cdot 1 \mathrm{~B} 2011-50)$.

\section{References}

(1) Lewis, N. S.; Crabtree, G. 2005.

(2) van de Krol, R.; Liang, Y.; Schoonman, J. Journal of Materials Chemistry 2008, 18, 2311.

(3) Sivula, K.; Le Formal, F.; Graetzel, M. Chemsuschem 2011, 4, 432. 4862.

(4) Lin, Y.; Yuan, G.; Sheehan, S.; Zhou, S.; Wang, D. Energy \& Environmental Science 2011, 4,

(5) Brillet, J.; Gratzel, M.; Sivula, K. Nano Letters 2010, 10, 4155. 
(6) Lin, Y.; Zhou, S.; Sheehan, S. W.; Wang, D. Journal of the American Chemical Society 2011, $133,2398$.

(7) Sivula, K.; Zboril, R.; Le Formal, F.; Robert, R.; Weidenkaff, A.; Tucek, J.; Frydrych, J.; Graetzel, M. Journal of the American Chemical Society 2011, 132, 7436.

(8) Steier, L.; Herraiz-Cardona, I.; Gimenez, S.; Fabregat-Santiago, F.; Bisquert, J.; Tilley, D.; Gratzel, M. Advanced Functional Materials 2014, DOI: 10.1002/adfm.201402742.

(9) Zandi, O.; Klahr, B. M.; Hamann, T. W. Energy \& Environmental Science 2013, 6, 634.

(10) Young, K. M. H.; Klahr, B. M.; Zandi, O.; Hamann, T. W. Catalysis Science \& Technology 2013, 3,1660 .

(11) Pendlebury, S. R.; Barroso, M.; Cowan, A. J.; Sivula, K.; Tang, J. W.; Gratzel, M.; Klug, D.; Durrant, J. R. Chemical Communications 2011, 47, 716.

(12) Pendlebury, S. R.; Cowan, A. J.; Barroso, M.; Sivula, K.; Ye, J.; Gratzel, M.; Klug, D. R.; Tang, J.; Durrant, J. R. Energy \& Environmental Science 2012.

(13) Peter, L. M.; Wijayantha, K. G. U.; Tahir, A. A. Faraday Discussions 2012.

(14) Upul Wijayantha, K. G.; Saremi-Yarahmadi, S.; Peter, L. M. Physical Chemistry Chemical Physics 2011, 13, 5264.

(15) Klahr, B.; Gimenez, S.; Fabregat-Santiago, F.; Hamann, T.; Bisquert, J. Jounal of the Americal Chemical Society 2012, 134, 4294.

(16) Klahr, B.; Gimenez, S.; Fabregat-Santiago, F.; Bisquert, J.; Hamann, T. Energy \& Environmental Science 2012, 5, 7626.

(17) Barroso, M.; Pendlebury, S. R.; Cowan, A. J.; Durrant, J. R. Chemical Science 2013, 4, 2724.

(18) Barroso, M.; Cowan, A. J.; Pendlebury, S. R.; Grätzel, M.; Klug, D. R.; Durrant, J. R. Journal of the American Chemical Society 2011, 133, 14868.

(19) Barroso, M.; Mesa, C. A.; Pendlebury, S. R.; Cowan, A. J.; Hisatomi, T.; Sivula, K.; Grätzel, M.; Klug, D. R.; Durrant, J. R. Proceedings of the National Academy of Sciences 2012, 109, 15640.

(20) Iwasita, T. Electrochimica Acta 2002, 47, 3663.

(21) Hoffmann, M. R.; Martin, S. T.; Choi, W.; Bahnemann, D. W. Chemical Reviews 1995, 95, 69.

(22) Kho, Y. K.; Iwase, A.; Teoh, W. Y.; Madler, L.; Kudo, A.; Amal, R. Journal of Physical Chemistry C 2010, 114, 2821.

(23) Lu, H.; Zhao, J.; Li, L.; Gong, L.; Zheng, J.; Zhang, L.; Wang, Z.; Zhang, J.; Zhu, Z. Energy \& Environmental Science 2011, 4, 3384.

(24) Chen, J.; Ollis, D. F.; Rulkens, W. H.; Bruning, H. Water Resources 1999, 33, 669.

(25) Mora-Sero, I.; Villarreal, T. L.; Bisquert, J.; Pitarch, A.; Gomez, R.; Salvador, P. Journal of Physical Chemistry B 2005, 109, 3371.

(26) Villarreal, T. L.; Gomez, R.; Neumann-Spallart, M.; Alonso-Vante, N.; Salvador, P. Journal of Physical Chemistry B 2004, 108, 15172.

(27) Baltrusaitis, J.; Hu, Y.-S.; McFarland, E. W.; Hellman, A. ChemSusChem 2014, 7, 162.

(28) Dotan, H.; Sivula, K.; Gratzel, M.; Rothschild, A.; Warren, S. C. Energy Environ. Sci. 2011, 4,

958.

(29) Klahr, B. M.; Hamann, T. W. Journal of Physical Chemistry C 2011, 115, 8393.

(30) Shen, M.; Henderson, M. A. The Journal of Physical Chemistry Letters 2011, 2, 2707.

(31) Panayotov, D. A.; Burrows, S. P.; Morris, J. R. The Journal of Physical Chemistry C 2012, 116, 6623.

(32) Cummings, C. Y.; Marken, F.; Peter, L. M.; Tahir, A. A.; Wijayantha, K. G. U. Chemical Communications 2012.

(33) Braun, A.; Sivula, K.; Bora, D. K.; Zhu, J.; Zhang, L.; Graetzel, M.; Guo, J.; Constable, E. C. Journal of Physical Chemistry C 2012, 116, 16870.

(34) Iandolo, B.; Hellman, A. Angewamdte Chemie International Edition 2014, 126, 1.

(35) McDonald, K. J.; Choi, K. S. Chemistry of Materials 2011, 23, 1686.

(36) Le Formal, F.; Tetreault, N.; Cornuz, M.; Moehl, T.; Gratzel, M.; Sivula, K. Chemical Science

2011, 2, 737. 
1

2

3

4

5

6

7

8

9

10

11

12

13

14

15

16

17

18

19

20

21

22

23

24

25

26

27

28

29

30

31

32

33

34

35

36

37

38

39

40

41

42

43

44

45

46

47

48

49

50

51

52

53

54

55

56

57

58

59

60

(37) Cowan, A. J.; Barnett, C. J.; Pendlebury, S. R.; Barroso, M.; Sivula, K.; Grätzel, M.; Durrant, J. R.; Klug, D. R. Journal of the American Chemical Society 2011, 133, 10134.

(38) Wang, X. G.; Weiss, W.; Shaikhutdinov, S. K.; Ritter, M.; Petersen, M.; Wagner, F.; Schlögl, R.; Scheffler, M. Physical Review Letters 1998, 81, 1038.

(39) Klahr, B.; Hamann, T. The Journal of Physical Chemistry C 2014, 118, 10393. 